\title{
Taking the heterogeneity of citizens into account: flood risk communication in coastal cities - a case study of Bremen
}

\author{
T. Martens ${ }^{1}$, H. Garrelts ${ }^{2}$, H. Grunenberg ${ }^{3}$, and H. Lange ${ }^{2}$ \\ ${ }^{1}$ German Institute for International Educational Research, Frankfurt a. M., Germany \\ ${ }^{2}$ Research Center for Sustainability Studies, University of Bremen, Germany \\ ${ }^{3}$ Institute for Environmental and Sustainability Communication, Leuphana Unviversity Luneburg, Germany
}

Received: 1 March 2009 - Revised: 25 September 2009 - Accepted: 12 October 2009 - Published: 24 November 2009

\begin{abstract}
The likely manifestations of climate change like flood hazards are prominent topics in public communication. This can be shown by media analysis and questionnaire data. However, in the case of flood risks an information gap remains resulting in misinformed citizens who probably will not perform the necessary protective actions when an emergency occurs. This paper examines more closely a newly developed approach to flood risk communication that takes the heterogeneity of citizens into account and aims to close this gap. The heterogeneity is analysed on the meso level regarding differences in residential situation as well as on the micro level with respect to risk perception and protective actions. Using the city of Bremen as a case study, empirical data from $n=831$ respondents were used to identify Action Types representing different states of readiness for protective actions in view of flood risks. These subpopulations can be provided with specific information to meet their heterogeneous needs for risk communication. A prototype of a computer-based information system is described that can produce and pass on such tailored information. However, such an approach to risk communication has to be complemented by meso level analysis which takes the social diversity of subpopulations into account. Social vulnerability is the crucial concept for understanding the distribution of resources and capacities among different social groups. We therefore recommend putting forums and organisations into place that can mediate between the state and its citizens.
\end{abstract}

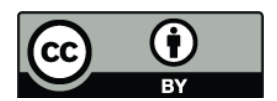

Correspondence to: T. Martens (martens@dipf.de)

\section{Introduction}

As far as climate change is concerned, the task at hand is no longer solely to avoid additional future impacts and to reduce the emission of so-called "climate gases". In view of the effects of entries into the climate system that can be foreseen already, the two recent large IPCC assessment reports (IPCC, 2001, 2007) have both emphasised the increasing need for adaptation in society; adaptation is aimed at reducing vulnerability.

With regard to one crucial effect of climate change, that is the growing incidence of high tides, several options are principally available to industrial nations such as Germany. At present, the scope ranges from technical measures (e.g. improvement of forecasts, constructing or reinforcing protective walls against the tide) to altered concepts for regional planning (e.g. prohibiting settlements in areas at risk of flooding) as well as measures for informing the public so that people can be proactive and are better prepared (IPCC, 2007, $143 \mathrm{pp}$.). This contribution focuses on the latter aspect in particular. The central question is: how can the public be informed more effectively regarding climate change and the subsequent increased incidence of high tides?

This leads to a whole range of other questions. First and foremost, we need to ask what should be the contents of communication. No absolute knowledge exists in the context of climate change with unpredictable dynamics and reciprocally aggravating effects (cf. UBA, 2008). Providing the public with information about climate change consequences is hence less subject to information policy, but rather a matter of risk communication. Risk communication can be described as a process of dealing with the uncertainties and unpredictability of future damage. How can the probability and the damage or dimensions of damage be assessed? How is risk and environmental knowledge best communicated?

Published by Copernicus Publications on behalf of the European Geosciences Union. 
How can so-called communication risks and related conflicts be dealt with, e.g. contradictory effects of risk communication? What roles do the issues of power play, as brought forward in particular by decision makers (Ruhrmann, 2003)?

Hence, it is clear that risk communication takes place in an area of conflict - being carried out by different groups of actors whose distinct perspectives shall be considered in this contribution. This area of conflict includes stakeholders from politics and administration, scientists in the domain of climate change, the media and citizens.

Political and administrative stakeholders at regional and community levels are facing difficult tasks. Dramatic events such as storm floods and high tides are particularly disconcerting for those who are potentially affected. However, the respective consequences of climate change at a regional level can only be described as possible, more or less probable occurrences. It is thus very likely that the responsible authorities tend to be cautious and reluctant in this respect. On the whole, risk communication holds a conflicting relation with the discourse on safety; this has so far been identified in the region of the German North Sea coast and it is controversially discussed by the authorities (Lange et al., 2008). One of the reasons is that many stakeholders do not think they have sufficient information for a proper assessment of the situation. Furthermore, they do not want to alarm and upset the population by indicating possible events while neither the time nor the likelihood of their taking place are certain. In consequence - and this is a problem - this means that the communication of flood risks by the administration may be very restrictive and is on the whole considered to be "problematic" (Lange et al., 2008; see also Lange and Garrelts, 2007a, b).

Meanwhile, the communication of risks takes place, via different channels of information. In particular, risks are communicated by the media. The (mass) media play an important role in the larger and more active public debate on climate change. For a long time they have offered climate research a public forum in which science has acted as a protagonist. Without this function of the media, public awareness for issues of climate change would never have reached the extent it has today. Climate research now has considerable power to define the terms of the debate (Weingart et al., 2002). However, the media are increasingly playing an independent role. We can see that the mass media do not simply act as transmitters of messages from other actors. Rather, they formulate and reconstruct them according to their own rules (Peters and Heinrichs, 2005). This is especially true when heterogeneous single extreme events, such as flooding, storms, dry spells and the overarching topic of global climate change, are linked together (Peters and Heinrichs, 2005). Climate scientists have not limited themselves solely to interpreting data, but for both society and especially for politics they have formulated concrete demands as to what needs to be done despite remaining uncertainties.
With regard to the affected citizens, questionnaires at any rate show that concerning climate change the public has, to put it colloquially, finally "caught on". Climate change is now considered one of the most important risks that societies as a whole, as well as each individual citizen on their own, must come to terms with, particularly in the future. Flooding is a similar, if smaller risk (Grunenberg and Kuckartz, 2003; Reusswig, 2006). The reluctance of experts in the politicaladministrative system to speak out on the topic of existing and future risks does not reduce irritation and worries; instead it creates additional irritation, as individual citizens feel they have been abandoned in the midst of the conflicting messages of the public discourse. If we thus ascertain the need for a communication of risks, accounting for the heterogeneity of the population presents a particular challenge. This can be described from a psychological perspective at the individual level, or from the sociological perspective at the societal level. Differences regarding access to climate-relevant information, for example, represent just one criterion among others (socio-economic status, age, language skills etc.), which are decisive determinants of social vulnerability. This concept explains the degree of damage in the wake of natural hazards less by the intensity of the event, but rather by the affected citizens' lack of capacities, which, for example, existed even before occurrence of the flood (Fordham, 2003; Wisner et al., 2004).

Our starting point is that determining acceptable levels of risk (and corresponding needs to take action) requires societal negotiation among potentially affected actors. This is especially important because as a rule each risk level has different consequences for different individuals. On the other hand, though, the societal negotiation which is needed for legitimisation cannot take place only in democratic institutions (majority rule in parliament and committees as well as in highly specialised administrative departments and offices). On the contrary, "reflexive modernisation" (Beck, 1993) ${ }^{1}$ requires an opening of the decision-making structure and the production of partially public spheres. The opening of the decision-making structure is accompanied by the requirement of an informed public. This is also a question of pragmatic consideration, since such an informed public is the only means of preventing disproportionate fears that are grounded in incomplete information. If flood protection is to

\footnotetext{
${ }^{1}$ The sociologist Beck conceptualises "reflexive modernization" as follows: Society is increasingly confronted with the consequences of past decisions about industrial growth processes that were originally hardly anticipated or the dynamics of which were underestimated. Thus, the industrial society starts turning into a risk society (Beck, 1993, p. 36). Beck distinguishes the following aspects as characteristics of political action in a risk society: demonopolisation of expertise, informalisation of authority, opening of decision-making structures, production of a greater variety and newer forms of the public sphere (Beck, 1993 pp. 190f.). The theme of climate change clearly expresses all of these tendencies toward changing the political landscape.
} 
be effective, both in the sense of prevention and in the sense of coping with extreme events, then there is a need for an informed population.

The following contribution looks at this question in two steps.

In a first step, we discuss whether and to what extent the public should be informed about extreme events. We discuss this issue against the background of a representative survey conducted in Bremen, and for reasons of comparison, in Hamburg also. These two German coastal cities are exposed to sea floods and high river tides in a very similar way. The survey focuses on the question as to how real the population assesses the danger of climate change and resulting consequences for their own lives to be.

In a second step, we introduce two options for improving the communication of risks. Both of them are aimed at reducing vulnerability by taking into consideration the social characteristics of citizens; while one of them relates to different dispositions of human beings with respect to coping with risk (psychological dimension), the other addresses specific forms of vulnerability in different social groups (sociological dimension).

This article is based on a research project carried out by a number of research institutions at German universities between 2005 and 2007 with the title "Integrated Flood Risk Management in an Individualised Society" (INNIG). It included case studies of Bremen and Hamburg. For their generous financial support we would like to thank the Federal Ministry of Education and Research. ${ }^{2}$

\section{The information environment in Bremen}

As part of the INNIG project we wanted to gain knowledge about how potentially affected individuals in Bremen inform themselves about "flooding" (cf. Heinrichs and Grunenberg, 2009). The surveyed means of communication in descending order of importance are depicted in Fig. 1.

In order to investigate the situation of flood risk communication in Bremen more closely, several aspects will be compared with Hamburg. Both Hamburg and Bremen are cities in Northern Germany situated on the estuaries of large rivers (the Weser and the Elbe). The geographical situation of these two cities implies very similar risk and vulnerability patterns for floods, nevertheless resulting in - and this will be demonstrated - very different approaches to risk communication.

In Bremen the most important means of accessing information were the classical mass media, radio and television. It is remarkable that radio is ranked slightly ahead of television, as in most other areas of life the television is considered to be significantly more important. In Bremen newspapers and magazines were in third place. The high ranking assigned to participation procedures in flood protection was somewhat

\footnotetext{
${ }^{2}$ For details, see http://www.innig.uni-bremen.de.
}

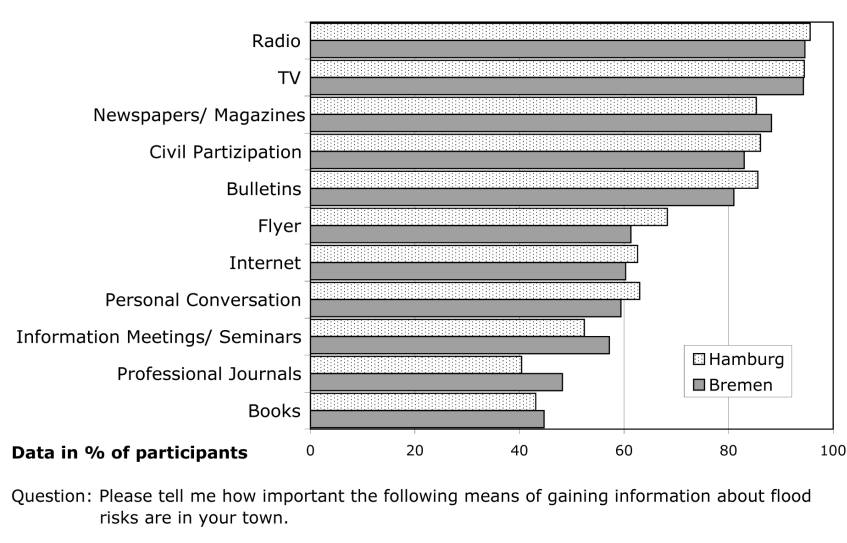

Fig. 1. Significance of information channel in flood protection.

surprising; after all it is the fourth most important means of collecting information. Official bulletins round off the top five ranking. Residents affected by flooding use one of these five means for obtaining most of the information they require. Leaflets, personal talks and the internet are ranked lower.

We asked more detailed questions about two information channels, namely about how comprehensive the reporting by newspaper, radio and television is, as well as information issued by the authorities. The analysis shows that for both questions the citizens of Bremen thought the reporting in their city was less comprehensive than the citizens of Hamburg did. In Hamburg $74.1 \%$ of those surveyed responded that media information was "very comprehensive" or "somewhat comprehensive", while in Bremen it was only $56.7 \%$. This is a significant difference that indicates an apparent imbalance. Compared with Hamburg, the population of Bremen is thus far from having a similar level of satisfaction as to the extent of information flow from their local media. We can also observe in our qualitative research part (Focus Group Interviews) that there is a considerable need for more media information among the inhabitants of Bremen, and that they are not disinterested in the topic.

The difference is even greater for the second question about the comprehensiveness of information issued by the municipal authorities. While in Hamburg 61.9\% consider the information from the authorities to be comprehensive, in Bremen it is only $36.4 \%$. Respondents to the survey hence think the main deficit results from the insufficient extent of information issued by the Bremen authorities. In addition to these questions about quantity, we also asked about the contents of media reports concerning flood protection organisation and measures. The responses in both cities hardly diverge at all, with a total of $74.9 \%$ considering reporting to be adequate, and $20.7 \%$ believing reporting is too uncritical. Only $4.5 \%$ find that the reporting is too critical. These numbers illustrate what is empirically confirmed by an inventory of available official information. While in Hamburg, we found a great 
variety of widely distributed brochures and an internet website with additional information for the reference period until 2006; in Bremen on the other hand we found few resources dealing with the subject. In Hamburg there are between 911 official brochures (depending on the definition), while in Bremen there are only two. One of the documents, which is distributed to over 109000 households in Hamburg, is a detailed brochure on protection in case of a disastrous flooding event and a leaflet giving locally specified information about storm flooding for the population living in flood-prone areas. Furthermore, there is an internet website with additional information about flooding protection in Hamburg. ${ }^{3}$ These examples illustrate the different strategies of hazard communication in Hamburg and Bremen. Hamburg has - so far taken a much more pro-active and differentiated approach to flood risk communication.

In order to investigate the qualitative dimension of the media, a sample was taken of daily printed media from the years 2001-2005. The results presented in the next paragraph are based on these analyses. In the sampling period a total of 108 newspaper articles in the local press of the city of Bremen and 161 in Hamburg refer to flooding in a broader sense. The following frequency distributions are based on this text corpus. It should be noted that these frequency differences are not necessarily significant, as the media landscape in Hamburg is considerably more differentiated than in Bremen, resulting in a greater total number of articles.

The printed media differ more clearly from each other in their content. The most frequent topic in both cities is protective measures against flooding, followed by the description of damages, which is mentioned in almost every tenth article. In Bremen the aspect of weather-related flooding due to a storm surge from the North Sea is not found in the media samples at all. Instead they deal exclusively with river flooding by the Weser. This occurs in $9.3 \%$ of all the texts sampled. In Hamburg both storm surges and river flooding were mentioned to almost the same degree. This distribution gives us an important indication as to the perception of local risk sources. It is remarkable that in Bremen hardly any reports mention possible future dangers. There is a tendency in the print media in Bremen to portray the feeling of safety as a result of technical protection alone. Technical protection, mostly in the form of dyke construction, is considered to be adequate in Bremen. In Hamburg the situation is portrayed differently in the local press. Although there are reports about the value of technology and its importance for the city's safety, there is an additional dimension concerning social and organisational precautionary measures. These measures include the development and availability of evacuation plans as well as the conduct of regular evacuation exercises. This aspect of reporting, which is not found in Bremen, corresponds to the

\footnotetext{
${ }^{3}$ The information system developed in this project is online since 15 September 2009: http://innig.tzi.de/innig/?id=48\&logintype= login\&user $=$ anonymous $\&$ pass $=$ anonymous $\&$ pid $=42$
}

idea of treating the population as individuals capable of acting responsibly in situations of risk and disaster.

Many group interviews revealed that there is a kind of oral tradition in Hamburg regarding flooding, mostly about the disaster that occurred in 1962, causing 315 casualties in Hamburg (in contrast to 7 casualties caused by the same flood event in Bremen). The 1962 flooding event can even be seen as an identity-defining moment for the population. Such an instance is completely lacking in Bremen where no recent local history of flood damage events is observable. Associations with flooding are thus more likely to be trivialised or even given a positive connotation in Bremen.

Compared to Hamburg, the perceived information environment in Bremen shows a quantitative deficit regarding mass media (radio, television, newspapers). There is an even larger gap concerning the information issued by public authorities. As discussed in the introduction the authorities in Bremen might be reluctant in this matter, but the next section proposes a scientific grounded approach to narrowing this gap without fuelling fears. For this purpose possibilities of preparing target-group specific communication with the help of the internet are systematically and empirically analysed and then realised as a prototype.

\section{Flood related Action Types and the tailoring of information}

In the following paragraphs, the theoretical and empirical basis for a web-based information system will be presented. The Internet is the medium where a very high number of requests can be processed with comparably low effort, so it is the most cost-effective mass medium for information providers. Furthermore, potential users can be addressed individually by means of computer algorithms, hence the Internet can handle population heterogeneity much better than any other mass media that probably need to use segmentation strategies (e.g. Slater and Flora, 1991, p. 740). Of course, measures for risk communication using the internet should be complemented with other information channels (see Sect. 4).

Individual differences regarding the perception of flood risks and resulting protective actions represent the heterogeneity of a population in psychological terms (see Plattner et al., 2006). It is not the objective risk of encountering a dangerous flood situation, but the subjective perception and individual appraisal that will trigger protective actions (Grothmann and Reusswig, 2006). The process of determining population heterogeneity on the basis of psychological theory starts with the "Motivation-Intention-VolitionModel (MIV)" (Martens et al., 1998). This model specifies cognitions and affects relevant for environmentally sound behaviour and their interactions. It integrates motivational psychology, action and social psychology (cf. Heckhausen, 1991; Schwarzer, 2004) and defines the action generating process in three phases: the "motivation phase", the "action 


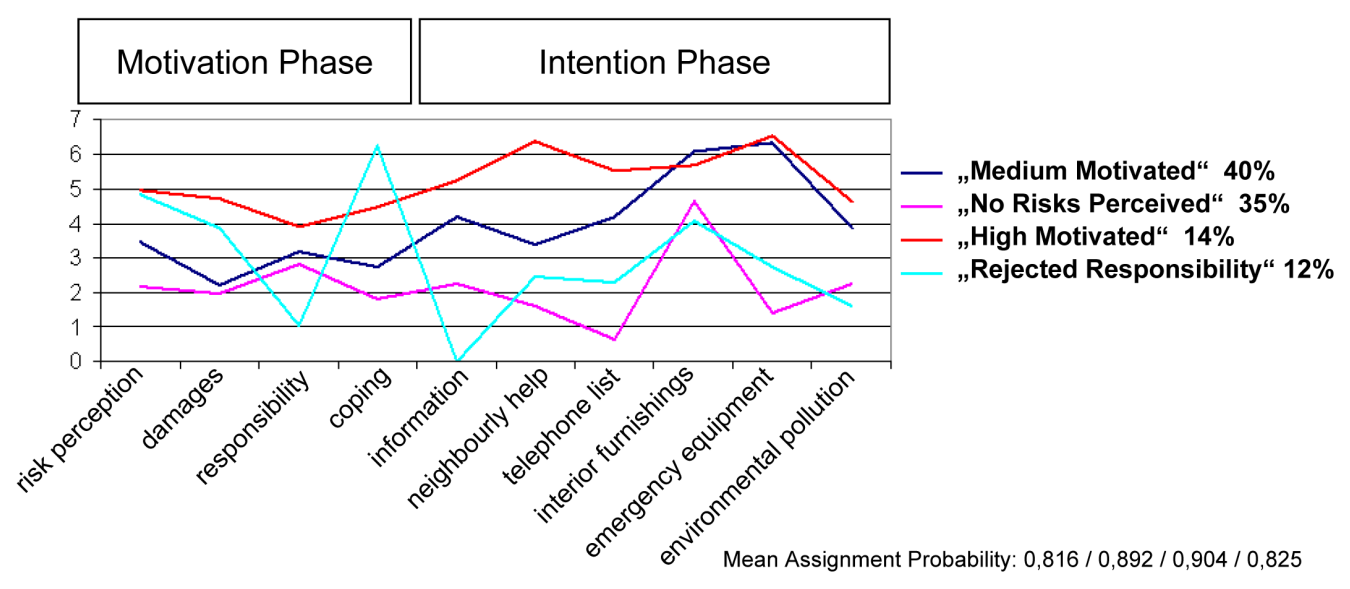

Fig. 2. Action Types that represent different states of readiness for protective actions regarding flood risks.

choice phase" and the "volition phase". Each of these phases is characterised by distinct cognitions and affects.

The motivation phase starts with a perception of threat which is based on the concept of "perceived vulnerability" (see Rogers, 1983) and in this study, it is combined with the concept of "expected damage" caused by a potential flood situation (see also Grothmann and Reusswig, 2006).

The formation of a "motive" also depends on two intervening processes:

- The coping style (cf. Krohne, 1986) is characterised by different strategies of reacting to hazardous situations, for example information seeking, denying, planning the future, distraction. People who possess a vigilant cognitive strategy try to obtain more information about the threat. Persons using a strategy of cognitive avoidance suppress perceptions of flood water threat and therefore probably do not develop a further motivation for protective actions.

- A second major cognition which is part of the motivation process is the feeling of "responsibility" for the solution of flood problems. Individuals might think that only the administration is responsible for solving floodrelated problems.

The intention phase is entered when a person is motivated to reduce an environmental threat through reflections about specific actions. The development of an intention is influenced by the following expectancies:

- outcome expectancy (Do you consider the following protective measures for avoiding a flood situation to be effective?) (cf. Heckhausen, 1991)

- self-efficacy (To which degree are you able to perform these protective actions in your own household?) (cf. Bandura, 1977)
- effort (How great will the effort be to realize the protective actions?)

The volition phase describes the process leading from intention to action. To perform an action successfully, situative resources and barriers play an important role. Self-control strategies and the social context are also relevant. This transformation of intention into action is the object of volition theory (cf. Heckhausen, 1991). The theoretical concepts of this phase were not used for identifying the Action Types but will be merged into the tailored information system.

On the basis of the MIV-Model, distinct scales were developed and surveyed with a telephone interview $(n=589)$ and an online questionnaire $(n=242)$.

The process of identifying distinct types follows the recommendations of Martens $(1998,2000)$ with three steps of analysis. At first, distinct scales that represent the motivation phase were measured. In a second step, the constructs that represent the intention phase were measured together according to the protective action they are assigned to. Finally, the results of the first two steps were used to conduct a latentclass analysis (Lazarsfeld and Henry, 1968) for identifying Action Types, thus disclosing the heterogeneity of a population.

Four Action Types emerge when balancing the factors that represent distinct aspects of the result quality (information criteria, data simulation and practical considerations) (see also Martens, 2007; Martens et al., 2008), representing different states of readiness for protective actions regarding flood risks. According to the latent-class analysis (Lazarsfeld and Henry, 1968) the subjects are assigned to the subpopulation or type that is most similar to the own profile of underlying measurement scores.

The first action (see Fig. 2) type called "Medium Motivated" ( $40 \%$ of the sample) reveals a moderate motivation and a moderate intention for three protective actions (collecting information, helping in the neighbourhood, creating a telephone list) and high intentions for the three remaining 


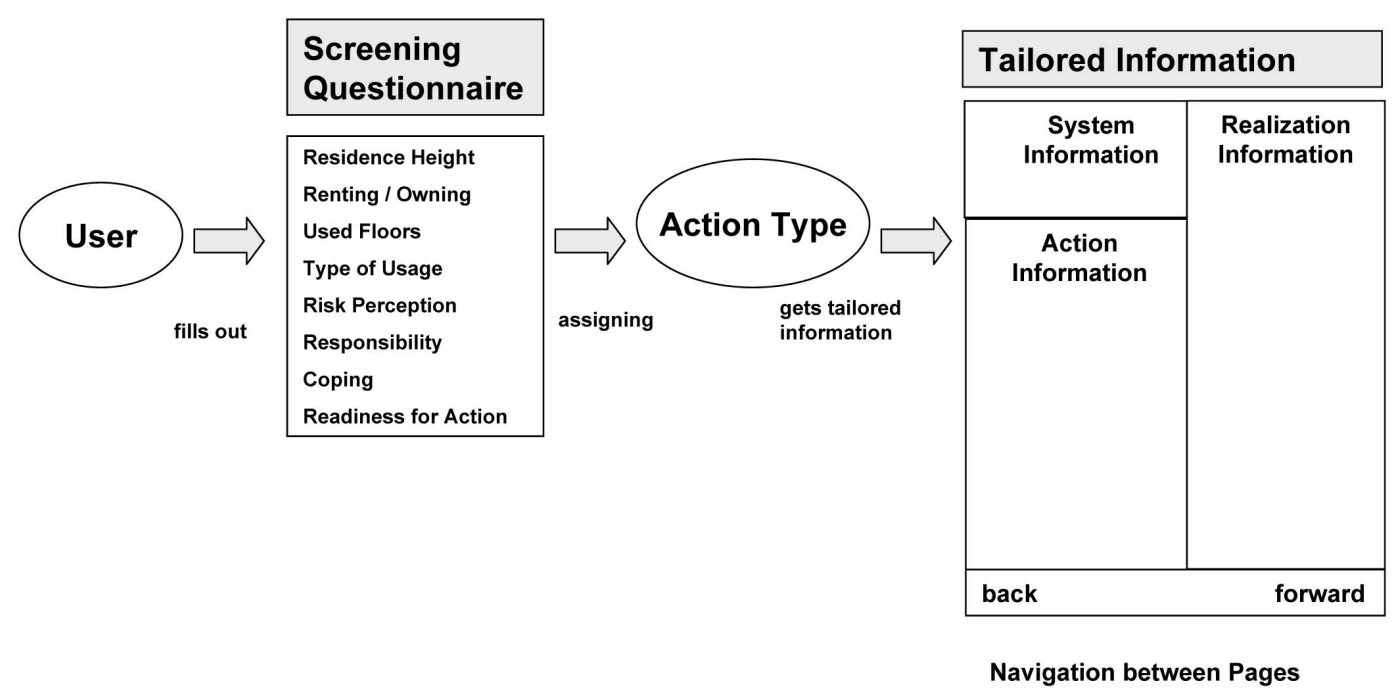

Fig. 3. Screening questionnaire and tailored flood information.

actions (measures to protect interior decorations, preparing emergency equipment, and avoiding environmental damage). The second Action Type called "No Risks Perceived" (35\%) shows a low motivation resulting in low intentions. The third Action Type called "Highly Motivated" (14\%) displays the opposite pattern: a high motivation resulting in high intentions for all protective actions. The fourth Action Type called "Rejected Responsibility" (12\%) shows an interesting motivational interaction: despite a high level of "perceived risk" and a "vigilant coping style" the "attribution of responsibility" is very external - this means that the public administration is considered to be responsible for protective measures. Consequently, the subjects who are assigned to the type "Rejected Responsibility" are not very interested in protective actions, particularly not in "creating a telephone list" and "preparing emergency equipment".

In the next step, we identified tailored information for these four Action Types. The idea underlying this rationale was to provide compensatory information regarding the three phases of the MIV-model. For this purpose, we distinguish three kinds of knowledge: "system knowledge", which should influence the motivation phase, "action knowledge", which should affect the intention phase and "action realisation knowledge", which should have an impact on the volition phase (Martens, 2005).

Information units based on this knowledge typology were fed into a tailored flood information system that is accessible via the World Wide Web. A screening questionnaire consisting of 10 questions can be used for identifying the most probable Action Type and the living conditions (see Fig. 3).

The living conditions take the altitude of the habitation, the floor level, usage of the floors and children or people who cannot care for themselves into account.
Both sources of information - the Action Type and the living conditions - were pooled together to tailor the appropriate information.

In Fig. 4 an example for tailored information is given, taking the following assumption from the screening questionnaire into account: (1) residence altitude: less than $5 \mathrm{~m}$ above sea level, (2) lowest used floor: cellar, (3) utilisation: storage of toxic substances, (4) Action Type "Rejected Responsibility": high perceived risk and vigilant coping but no responsibility resulting in a low intention for protective actions. This example covers only information for one protective action depending on to the recipient's general motivation level more information on other protective actions is provided.

\section{The social vulnerability-approach and its relevance in Bremen}

Heterogeneity applies, as the previous section shows, to the level of individuals and to the dimension of "types". In the given context another level is of relevance - that of social groups. Social groups face extreme natural events with different capacities, or in terms of more recent approaches rooted in scientific disaster research, with varying degrees of vulnerability.

The social vulnerability approach represents an alternative to classical deterministic approaches that explain disasters by external factors such as the natural events' intensity and frequency or by technical failure. This classical view has been criticised in recent years (e.g. Blaikie et al., 1994; Cannon et al., 2003). Alternative explanations have been elaborated in different scientific contexts (e.g. political ecology, cultural geography) in order to overcome this determinism. As O'Keefe et al. put it (as early as 1976): "Taking the naturalness out of natural disasters". Within these approaches, the assumption that vulnerability exists independently of a 


\section{High Water Situation}

With an altitude of less than 5 metres above sea level, your settlement belongs to the low-level settlement areas in Bremen. However, the dykes provide sufficient protection. Nevertheless, recent years have shown an increase in extreme weather phenomena, and we cannot fully preclude that flooding might happen in Bremen.

If you wish to find out how the city of Bremen is protected, please click here.

\section{Protective action environmental damage}

You will surely have heard before that one drop of oil might spoil 600 litres of drinking water. Now imagine how much damage might be done to the environment if your cellar were flooded and you had stored containers of paints, varnish, chemical substances or cleansing solutions with equally toxic ingredients there. In case of flooding, these would cause lasting damage to the groundwater.

With little effort, you can preclude damages to the water and your own living quarters. After all, you want to live in a clean, healthy environment once the flood has subsided.

We have compiled some suggestions for you.

further protective action forward

\section{What can I do?}

Please keep polluting substances in higher stores that are not prone to be flooded.

When buying emulsion paint, please take care that it is produced on a water basis, thus the storage of leftover cans in the cellar would not harm the groundwater.

If damage should still be done to the groundwater, please call the fire service immediately so that damages can be removed early.

You can print out the complete list, and add further items, here.

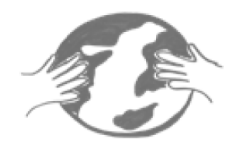

Risk Hazards

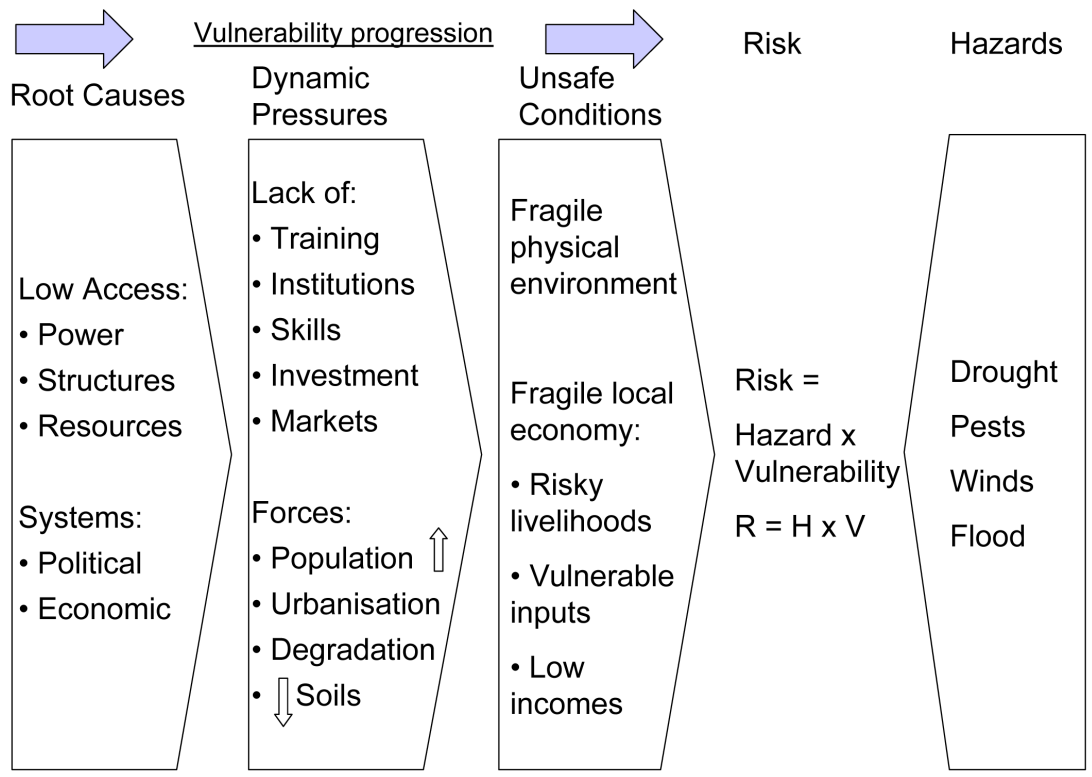

Fig. 5. "Pressures" that result in disasters (Wisner et al., 2004, p. 217, modified).

triggering hazard is of central importance. Thus, the multidimensional concept highlights the social production and especially the social differentiation of vulnerability. In sum, the analysis of vulnerability has lately focussed on issues of resource distribution and access to power as well as issues of legally formulated claims on education and knowledge (Dietz, 2006).
In the course of this debate, the access model of Blaikie et al. (1994) and Wisner et al. (2004) has attracted much interest. Blaikie et al. describe the cause of vulnerability as a dynamic process consisting of structural and political factors. Different political and economic dynamics "translate" societal asymmetries into unsafe conditions (see Fig. 5). Thus, rather than being defined in terms of function of damage and 
probability, risk is understood as a function of natural hazard and vulnerability.

Social vulnerability results from the interaction of two opposing factors. These are composed of those processes generating social vulnerability on the one hand, and the natural hazard event on the other (Wisner et al., 2004, p. 50). The former factors refer to the characteristics both of affected groups and space (e.g. lack of training, a fragile physical environment).

In order to determine the degree of social vulnerability, there is a consensus to take the following dimensions into account (Fordham, 2003; Thomalla et al., 2006; Wisner et al., 2004):

- distribution of income,

- access to resources such as information and knowledge,

- gender,

- skills in locally spoken language,

- ethnic affiliation,

- the age group, with relevance both to young and elderly people,

- potential disabilities,

- access to and integration in networks.

These factors are not static, they are, in fact, characterised by political and economic dynamics.

According to our interviews with representatives of the political-administrative system (Lange and Garrelts, 2007a), for bigger cities in Germany such as Bremen the following dynamics and trends are increasingly relevant:

- demographic change. This is relevant with regard to an increasing number of vulnerable elderly people who in particular have to be taken into account in terms of reduced mobility;

- immigration as a second dimension of demographic change. In the given context, the lack of German language skills represents an important aspect in terms of social vulnerability. For example, flood warnings transmitted by German radio stations might not be understood. In our interviews, officers of the (professional) fire brigade and civic protection highlighted cases which revealed severe obstacles to accomplishing the rescue mission at hand because of hindered or even impossible communication between rescue party and victims. Another recorded problem is the perception of flood risks as a paralysing and fateful threat. In addition, officers wearing uniforms are often unwanted helpers (Lange and Garrelts, 2007a, 102ff. and 125ff.).
- individualisation with an increasing number of oneperson households; in addition, increased job-market mobility combined with disaggregating of traditional cultural milieus, with far-reaching negative consequences for the flood risk awareness of new inhabitants (Pfeil, 2000).

- social disparities and social polarisation. Poverty and unemployment nowadays represent a lasting phenomenon with severe consequences for inner-city districts as well as for large suburban housing estates. Here, socially deprived areas are on the verge of becoming places of social disintegration which might, for example, lead to a deterioration of access to networks and information.

According to the concept of social vulnerability, shared and distinct reasons exist for treating poor persons, the elderly, and migrant citizens as well as the fraction of new inhabitants as particularly vulnerable. Owing to societal change and dynamics, these social groups are increasing in numbers and therefore the administration in charge of risk communication has to take these groups exceedingly into account. Our interviews revealed a crucial point of interest, that is a rather unspecific lack of resources for coping with extreme events. A lack of German language skills, for example, does not represent a problem until times of severe climate change. It is a severe restriction to coping with everyday risks such as fire incidents.

\section{Open flood communication - transition into practice}

\subsection{Taking the heterogeneity of citizens into account}

Deficits such as a lacking knowledge of the locally common language or the exclusion from helpful networks determine the abilities of the different social groups to cope with extreme events. For the system of flood protection, a need for target group orientation can be derived from this: on the one hand the specific needs of socially vulnerable groups such as the poor, the old, children, migrants and so-called new citizens should be met. On the other hand the portions of the previously described Action Types vary in the social groups, so tailored concepts of risk perception and risk coping should be applied. The proposed information system could be one measure to address this heterogeneity. Furthermore, the information system could be used by local authorities to improve official flood communication in Bremen. This would serve as a trustworthy source complementing commercial media communication. 


\subsection{Forums}

The corresponding tailoring should be supported by the possibilities provided by internet technologies. Therefore, the described internet platform offers a forum for tailoring target specific group concepts. Nevertheless, access and usage of the internet is still not available to everyone - the "town is digitally divided" (Einemann, 2006), hence complementary measures should be implemented, too. We recommend setting up forums and organisations that can mediate between the state and its citizens. In decentralised form, forums have existed in the form of round tables in many German towns since the 1980s and they have proven to be very useful for developing city quarters. Specifically, this concerns citizen-oriented organisations such as volunteer fire fighting departments or schools and sports facilities which can play an important role as multipliers in the context of target group specific strategies of risk communication.

\section{Outlook}

We argue in this paper that risk communication from the official side is essential with respect to accelerated climate change. More official communication provided, the citizens will be better informed and better prepared. On this basis, measures of flood and hazard protection will become more effective. Moreover, risk communication is also a matter of public legitimisation - the administration cannot decide single-handedly on mitigation and adaptation to risks pertinent to climate change. In addition to these theoretical reasons, this paper has delivered empirical evidence that information on climate change has already been delivered by the media and science. In both of the examined cities the citizens are very well-informed despite the cities' different characteristics like their historical background or the geographical location. Since risk communication is also a sensitive matter of trustfulness (Ruhrmann, 2003), we recommend that government agencies pursue an information policy that is transparent and well-balanced.

The research presented here aims at answering the question of how to shape and deliver information on the topic of storm floods. Based on the strong interconnection of theory and empirical results, the heterogeneity of the target population has to be considered on two levels:

- the heterogeneity of individuals is reflected by Action Types representing different stages of readiness for protective actions in case of flood.

- the heterogeneity of vulnerability in social groups which represent different levels of capacities for taking protective actions

Overall, the reported theoretical and empirical framework still needs to be completed. From the theoretical point of view the shift from the macro level (information environment) to the micro level (tailored information) back to the meso level (socially vulnerable groups; authorities in charge) is quite plausible. Of course, the given argumentation does not represent a fully integrated theory and the underlying framework has to be advanced further.

Moreover, fundamental research can be conducted by a control group trial on the community level or - much more sophisticatedly - by agent-based simulation that reflects the interactions of micro and macro processes (see Mosler and Martens, 2008).

Furthermore, applied research can be focussed on specific questions regarding the shaping and delivery of information:

- will the given information be accepted by the public and by the authorities?

- can the expected influence on information behaviour and enacting protective actions be proved?

- how can the content of the information platform be updated regularly and, in particular, how can the collected usage data (information behaviour, screening questionnaire) be used to improve the information system itself?

- how can participative elements of risk communication be embedded within the information platform?

- how can the proposed complementary measures of risk communication be embedded into an integrated framework? Especially, how can other information channels (e.g. mass media, forums) and other actors be more active?

Acknowledgements. The authors wish to thank the German Federal Ministry of Education and Research for funding the research project "Integrated flood risk management in an individualized society (INNIG)" and the two referees for their helpful comments.

Edited by: K. Günther

Reviewed by: two anonymous referees

\section{References}

Bandura, A.: Self-efficacy: Toward a unifying theory of behavioral change, Psychol. Rev., 84, 191-215, 1977.

Beck, U.: Die Erfindung des Politischen, Suhrkamp, Frankfurt, 1993.

Blaikie, P., Cannon, T., Davis, I., and Wisner, B.: At risk. Natural hazards, people's vulnerability and disasters, Routledge, London, 1994

Cannon, T., Twigg, J., and Rowell, J.: Social Vulnerability, Sustainable Livelihoods and Disasters. Report to DFID, Conflict and Humanitarian Assistance Department (CHAD) and Sustainable Livelihoods support Office, London, 2003.

Einemann, E.: Das Internet in Deutschland: Differenzierungen, Spaltungen, Kopplungen, Schüren Verlag, Marburg, 2006. 
Fordham, M.: Gender, disaster and development: the necessity for integration, in Natural Disaster and Development in a Globalizing World, Routlege, London, 57-74, 2003.

Grothmann, T. and Reusswig, F.: People at Risk of Flooding: Why Some Residents Take Precautionary Action While Others Do Not, Nat. Hazards, 38, 101-120, 2006.

Grunenberg, H. and Kuckartz, U.: Umweltbewusstsein im Wandel: Ergebnisse der UBA-Studie Umweltbewusstsein in Deutschland 2002, edited by: Umweltbundesamt, Leske + Budrich, Opladen, 2003.

Heckhausen, H.: Motivation and action, Springer, New York, 1991.

Heinrichs, H. and Grunenberg, H.: Klimawandel und Gesellschaft: Perspektive Adaptionskommunikation, VS-Verlag, Wiesbaden, 2009.

IPCC: Climate Change 2001: Impacts, Adaptation and Vulnerability. Contribution of the Working Group II to the Third Assessment Report of the Intergovernmental Panel on Climate Change, Cambridge, 2001.

IPCC: Climate Change 2007: The Physical Science Basis, Summary for Policymakers, Paris, 2007.

Krohne, H. W.: Coping with stress: Dispositions, strategies, and the problem of measurement, in: Dynamics of stress: Physiological, psychological, and social perspectives. The Plenum series on stress and coping, edited by: Appley, M. H. and Trumbull, R., Plenum Press, New York, 207-232, 1986.

Lange, H. and Garrelts, H.: Integriertes Hochwasserrisikomanagement in einer individualisierten Gesellschaft (INNIG), Teilprojekt 4: Politisch-administrative Steuerung, Endbericht, University of Bremen, 2007a.

Lange, H. and Garrelts, H.: Risk management at the science-policy interface. Two contrasting cases in the field of flood protection in Germany, Journal for Environmental Policy and Planning, 9, 263-279, 2007b.

Lange, H., Wiesner, A., Haarmann, M., and Voosen, E.: "Handeln nur auf der Basis sicheren Wissens". Die Konstruktion des Risikos aus Sturmfluten und Klimawandel im politischadministrativen System, in: Land unter? Klimawandel, Küstenschutz und Risikomanagement in Nordwestdeutschland: die Perspektive 2050, edited by: Schuchardt, B. and Schirmer, M., Ökonom, München, 145-166, 2008.

Lazarsfeld, P. F. and Henry, N. W.: Latent structure analysis, Houghton Mifflin, Boston, 1968.

Martens, T. and Rost, J.: Der Zusammenhang von wahrgenommener Bedrohung durch Umweltgefahren und der Ausbildung von Handlungsintentionen, Z. Exp. Psychol., 45, 345-364, 1998.

Martens, T., Rost, J., and Gresele, C.: Identifikation von kognitiven, affektiven und sozialen Faktoren des Umwelthandelns - Skalensammlung, in: ZUMA Informationssystem, Version 2.0, Elektronisches Handbuch sozialwisenschaftlicher Erhebungssysteme (CD-Rom, FTP), edited by: Gloeckner-Rist, A. and Schmidt, P., ZUMA, Mannheim, 1998.
Martens, T.: Kognitive und affektive Bedingungen von Umwelthandeln, dissertation.de, Berlin, 2000.

Martens, T.: Das Wissen maßschneidern, Politische Ökologie, 95, 35-37, 2005.

Martens, T.: Handlungstypen als Grundlage für die Maßschneiderung von umweltpsychologischen Informationen, Umweltpsychologie, 11, 69-87, 2007.

Martens, T., Erdwien, B., and Ramm, K.: Risikoverarbeitung und Risikoverhalten am Beispiel extremer Hochwasserereignisse, Schlussbericht für das Bundesministerium für Bildung und Forschung, Förderkennzeichen: 0330693C, Universität Bremen, 2008.

Mosler, H.-J. and Martens, T.: Designing environmental campaigns using agent-based simulations, J. Environ. Manage., 88, 805816, 2008.

O'Keefe, P., Westgate, K., and Wisner, B.: Taking the naturalness out of natural disasters, Nature, 260, 566-567, 1976.

Peters, H. P. and Heinrichs, H.: Öffentliche Kommunikation über Klimawandel und Sturmflutrisiken: Bedeutungskonstruktion durch Experten, Journalisten und Bürger, Forschungszentrum Jülich, 2005.

Pfeil, J.: Maßnahmen des Katastrophenschutzes und Reaktionen der Bürger in Hochwassergebieten. Am Beispiel von Bonn und Köln, Deutsches Komitee für Katatstrophenvorsorge, Bonn, 2000.

Plattner, Th., Plapp, T., and Hebel, B.: Integrating public risk perception into formal natural hazard risk assessment, Nat. Hazards Earth Syst. Sci., 6, 471-483, 2006, http://www.nat-hazards-earth-syst-sci.net/6/471/2006/.

Reusswig, F.: Argumente statt Panikmache. Die seriöse Berichterstattung hat in der Klimadebatte die Katastrophenschlagzeilen abgelöst, punkt.um, 3-4, 2006.

Rogers, R. W.: Protection Motivation Theory, J. Soc. Psychol., 211, 223-244, 1983.

Ruhrmann, G.: Risikokommunikation, in: Öffentliche Kommunikation, edited by: Bentele, G., Brosius, H.-B., and Jarren, O., Westdeutscher Verlag, Opladen, 539-549, 2003.

Schwarzer, R.: Stage models of health behavior change: Advances and problems, in: Research on the Trantheoretical Model: Where are we now, where are we going?, edited by: Keller, S. and Velicer, W. F., Pabst, Lengerich, 110-113, 2004.

Slater, M. D. and Flora, J. A.: Health lifestyles: Audience segmentation analysis for public health interventions, Health Educ. Quart., 18, 221-233, 1991.

Thomalla, F., Downing, T., Spanger-Siegfried, E., Han, G., and Rockström, J.: Reducing hazard vulnerability: towards a common approach between disaster risk reduction and climate adaptation, Disasters, 30, 39-48, 2006.

Weingart, P., Engels, A., and Pansegrau, P.: Von der Hypothese zur Katastrophe: Der anthropogene Klimawandel im Diskurs zwischen Wissenschaft, Politik und Massenmedien, Leske + Budrich, Opladen, 2002.

Wisner, B., Blaikie, P., Cannon, T., and Davis, I.: At risk. Natural hazards, people's vulnerability and disasters, Routlege, London, 2004. 